\title{
How Does Hybrid Project Management Create Value for Telecommunication Industry?
}

\author{
Wu Kuo-Wen \\ Feng Chia University \\ E-mail address_P0700318@mail.fcu.edu.tw
}

\begin{abstract}
The advent of smartphones and the emergence of instant messaging software have changed the ecology of the telecommunications industry, which has also led to a decrease in the profits of telecommunications companies year by year. In the face of the new generation of consumer groups with changing needs, Telecommunications operators have continued to improve their core capabilities. How to accurately grasp the needs of customers and respond quickly is one of the key capabilities for companies to create new opportunities. This paper discusses the operation of the three project management modes based on the improvement of the network service. It summarizes the way the project is carried out and its benefits analysis through the field research od and then uses the empathy analysis tool to make the project colleagues think in perspective and deeply understand the customer's pain points can also modify the function of the product (service) from customer feedback. The study found that if the hybrid project management model can be used well, in addition to speeding up the solution of customers' network usage problems, it can also reduce unnecessary high network construction costs, which is a way of generating high value for both the company and customers project management model.
\end{abstract}

Keywords: Hybrid project management, Agile project management, Create value

\section{INTRODUCTION}

This is an open access article under the CC-BY-NC license.

How to effectively allocate the company's important resources is usually achieved through the execution of the project in the hope of achieving the set strategic goals.

In the past, projects in the telecommunications industry were planned and executed in a traditional way because the capital invested in large-scale public network construction was quite large, from the initial selection of equipment manufacturers to the procurement of equipment, followed by the core network and optical fiber backbone. After the construction, etc., the system capacity must be calculated carefully. After the power, fire, and air-conditioning facilities of the computer room are built from the selected appropriate location, the core network equipment is installed, and then the optical fiber and bases are gradually deployed in various places according to the growth of the traffic. Taiwan's expansion of the mobile network and such careful and rigorous planning are nothing more than the hope that it can reduce the risks generated under uncertain circumstances and produce the expected results of the resources invested.

The advent of smartphones and the emergence of the Internet of Things have changed the industrial ecology. The rich and diversified products and services have changed the business model 
of existing telecommunications companies that only sell voice calls, and the profits of the telecommunications industry have become greater after the emergence of instant messaging software. Affected, the new generations rely more on social software and mobile networks as daily tools. In order to meet the needs of Internet users for innovation, change, and speed, it is also necessary to develop products and handle customer problems. Simplification and speed. If telecom operators do not strengthen network coverage and expand bandwidth as user needs change, the quality of network services will be affected. The inability to use the network to the fullest will also become a pain point for users, so how to strengthen the network Service quality has become one of the key competitiveness.

In the digital transformation process of the telecommunications industry, in addition to continuously improving the core capabilities of the industry (network quality, rich customer experience data, IT infrastructure and systems, and powerful channels), in the $5 \mathrm{G}$ era, it is also necessary to integrate big data, AI, and material Networking and cloud technology, so how to add agile thinking to the traditional project planning, use this sensitive project management model to accurately grasp the needs of customers and respond quickly, to find new opportunities for the company and create better for customers Value is the research purpose of this paper.

\section{LITERATURE REVIEW}

Project management originated in the U.S. defense industry and was later widely used in government departments to improve performance (Crawford LH, Helm J., 2009). The knowledge of these large-scale defense and government projects has evolved over the decades. Has gradually developed into a widely used management knowledge system (such as PMI, IPMA, and other societies' project management knowledge system guidelines), and because the defense industry and government infrastructure projects have invested a lot of money, there is no room for mistakes. Therefore, These projects must be planned in a clear context before detailed schedules, costs, resources, and manpower are planned (Roger Atkinsona, Lynn Crawford, \& Stephen Wardd, 2006)

The introduction of project management in the business community is a series of action plans that must be executed in order to improve the company's operational efficiency and transform the company's strategy into specific goals so as to make the most valuable product in a determined timeline and invested resources. Different from government projects (Tony Grundy, 1998), companies must evaluate and plan more carefully, because once the project fails, it may lead to serious losses or even bankruptcy (James P. Lewis, 2012). When planning, most of them adopt a more rigorous traditional project management model to avoid the risks brought by uncertainty.

Rao, R.(2007) proposed the Why-How Framework that project management is a key strategic tool that can promote these plans and help companies obtain business benefits. Rao believes that a successful strategy lies in the organization's hierarchical concept of goals. The way to measure the results of the strategy is different at each level. At the company level, the strategy is reflected in financial indicators such as ROI, cash flow and growth, customer satisfaction. Technical excellence and other aspects of the output. At the project portfolio level, the right project or plan should be selected. At the project level, the measurement indicators are usually in terms of scope, time, and cost, and sometimes customer satisfaction. He believes that project portfolio management is a vital part of linking strategy and project.

The origin of the concept of agile project management comes from the software and information industry. It is mainly derived from the needs of customers seeking innovation, change, and speed. It has also been widely used in various industries, such as the administration of internal customers. Improvements in facilities, streamlining of system processes, product development by external customers, and customer interface design have all produced amazing results. According to 
the research of Owen, Robert, Koskela, Lauri, Henrich, Guilherme, Codinhoto, and Ricardo (2006), there are significant benefits after adopting agile project management, and the results represented by these benefits are mainly:

1.Customers participate in the planning process and can respond to customer needs immediately.

2. Product performance is more in line with needs.

3. Shorten development time.

4. Reduce development costs.

The integration of traditional and agile is another change in project management. This model has been successfully applied in the IT industry. According to the research of Gordana Lozo \& Slobodan Jovanovic (2012), it shows that Agile project management and Traditional project management combined with hybrid project management is the most suitable solution, but whether it can be applied to the telecommunications industry is lacking in the literature. Therefore, the results of this research will establish a model for improving the quality of telecommunications networksreference for telecommunications practitioners.

\section{RESEARCH METHODOLOGY}

This research will use field survey methods, using observations and interviews on the job site to collect data. The research methods are described as follows:

1. Reasons for the choice of research method: Because the researcher has worked in this company for more than 20 years and has a good understanding of corporate culture, organizational climate, and the mode of project progress, which is helpful for data collection and recording;

2. Research objects: mainly engineering personnel involved in network planning, construction, maintenance, and handling customer network problems;

3. Research period: From August 2020 to September 2020;

4. Data analysis steps:

a. Collect historical data that have participated in network construction and improvement projects, and conduct summary analysis

b. Conduct semi-structured interviews with project team members to analyze the advantages, disadvantages, and effectiveness of the three project models

c. Use empathy maps for empathy, let each member of the project team have a deep understanding of the customer's ideas, and modify the product (service) function from the customer's feedback

\section{FINDING AND DISCUSSION}

The results of this research use the three project management modes to improve the quality of networks, as explained in below.

\section{IV.1 Traditional project management}

It can be used in the construction of access telecom Room and base stations (including search suitable location). Normally, the project construction period is more than two months, and then must be a clear scope before rebuilding do detailed planning for time, cost, resources, and manpower, A base station project construction plan is shown in Figure 1. 
Proceeding on Japan International Business and Management Research Conference (JIBM),

Vol. 1 (1), 43-48

How Does Hybrid Project Management Create Value for Telecommunication Industry? Wu Kuo-Wen

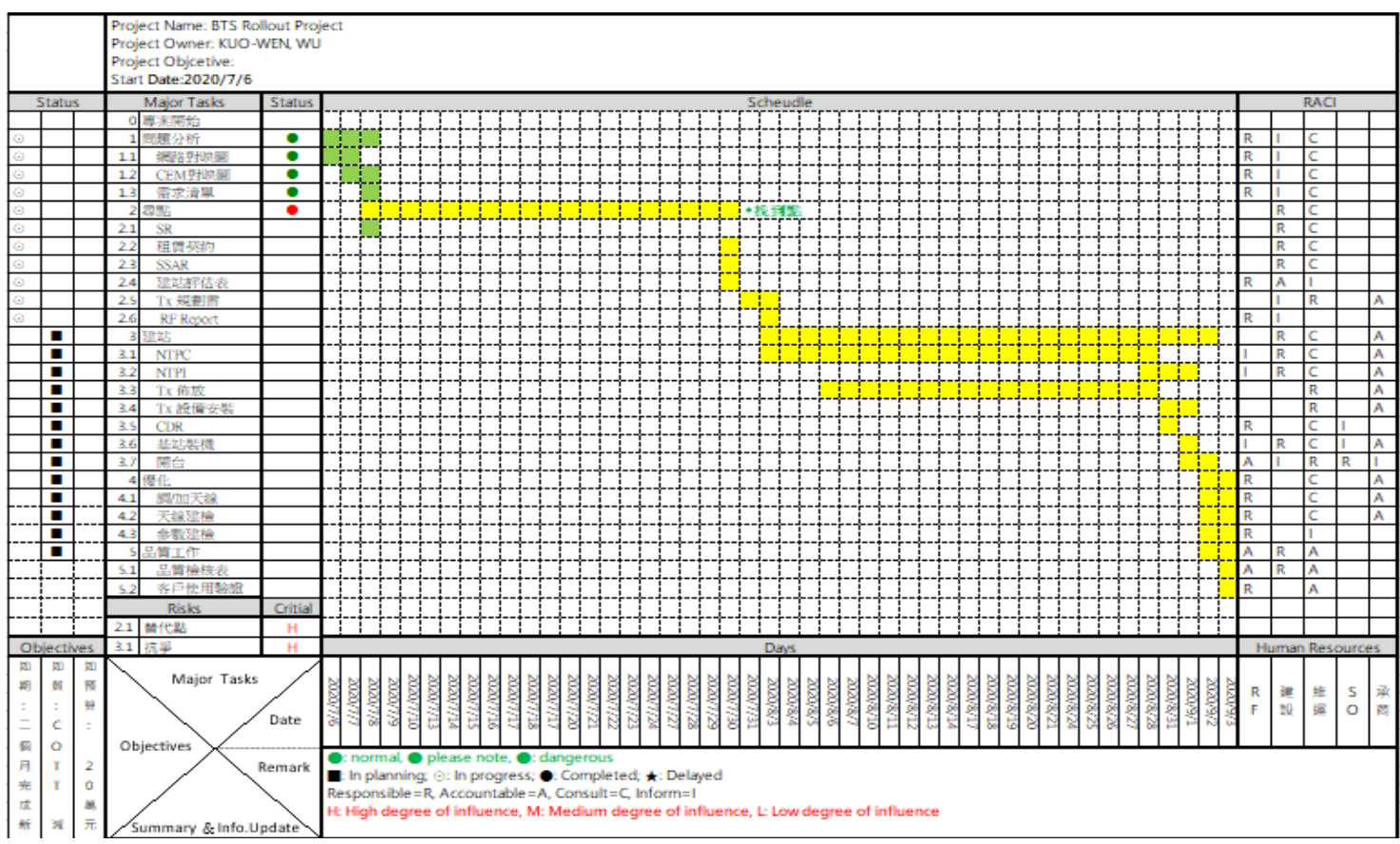

Figure 1. The project plan of base station construction(one page A4 plan)

\section{IV.2 Agile project management mode}

It can be used to strengthen the coverage deficiency (such as Addon cell, Antenna adjustment, Power adjustment, Parameters adjustment..), network capacity, and bandwidth expansion (tx expansion, and radio band expansion); these tasks are usually completed within a week, and after completion, quickly review with the customer to obtain the feedback, if not improve, enter the next iteration until the customer's problem is improved. A network optimization project plan is shown in Figure 2.

1. Release Plan

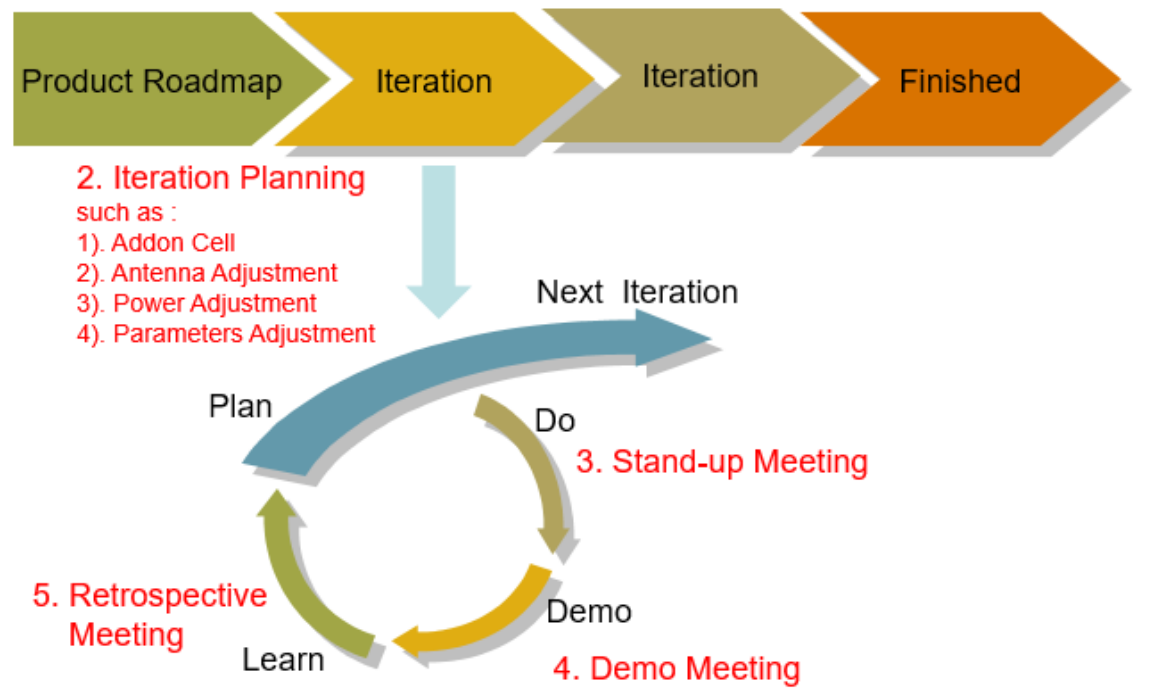

Figure 2. Network optimization by agile 


\section{IV.3 Hybrid project management mode}

Traditional + agile, usually a traditional network deployment plan first, because finding a suitable location is a long process, so in this process, you can use agile first the existing base stations in the surrounding area are adjusted gradually, and then compared with the customer's feedback (user experience) after adjustment. Usually after 2 to 3 iterations (about 2 to 3 weeks) of adjustment, good results can be obtained. This is done in batches. The concept of delivery solves the pain points of customers. Once the problem is improved, large-scale network construction can be stopped to avoid unnecessary network construction. The hybrid project mode, as shown in figure 3 .

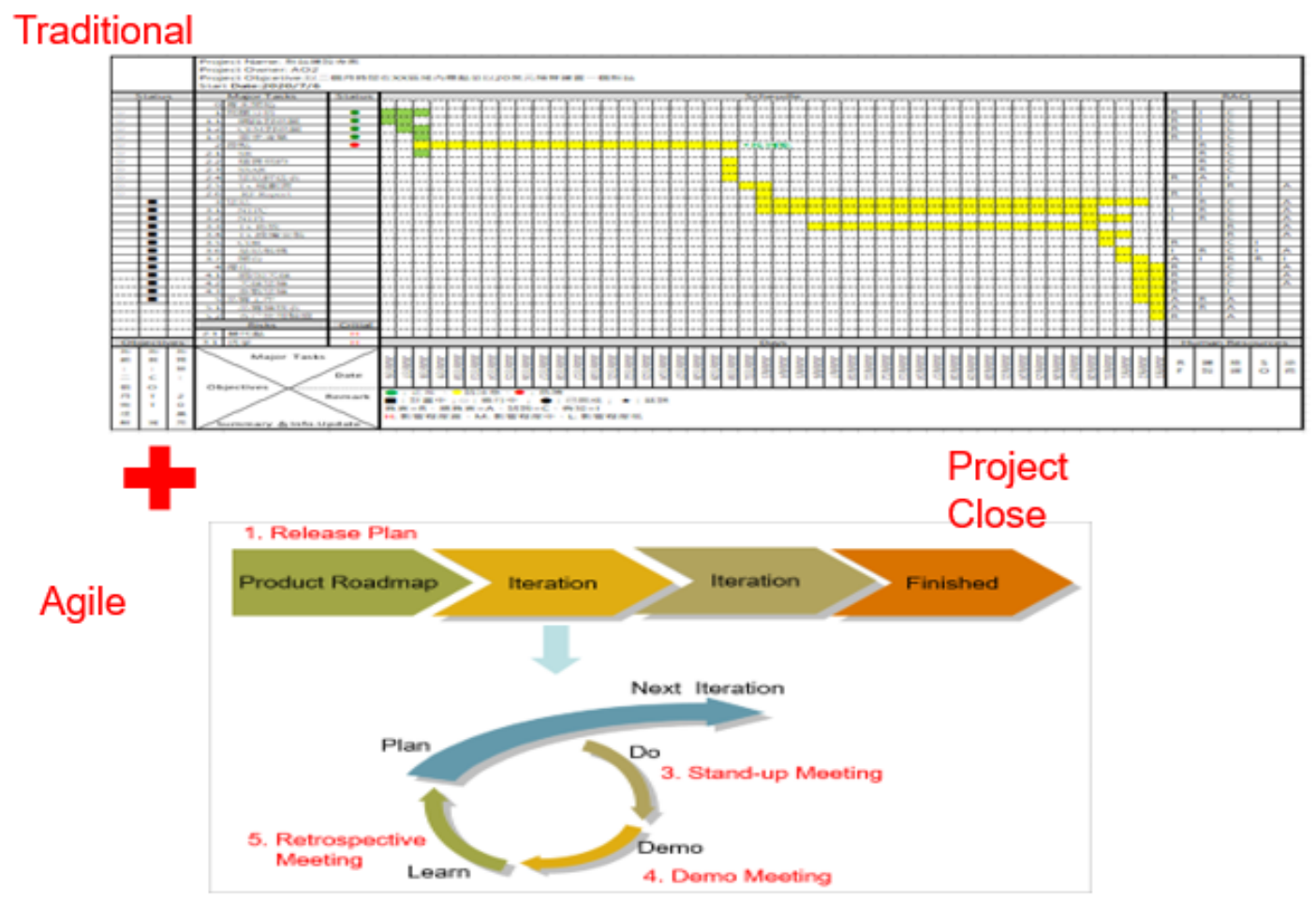

Figure 3. Hybrid project management of network improvement

An important finding can be obtained from the above research, that is, traditional project management is mostly applied to large-scale projects, and its rigorous planning can reduce the risks caused by uncertainty and can produce expected results for the invested resources; agile projects Manage the changing needs of customers that are suitable for uncertainties. Through customer participation and feedback, demand elicitation and rapid batch delivery can be carried out, which greatly shortens the project time; the hybrid type has the advantages of both.

\section{CONCLUSION AND FURTHER RESEARCH}

This research use field research methods to explore the application of three project models to improve the network quality of the telecommunications industry. The research results show that if these three modes are fully used in various situations, they will achieve quite good results. Traditional projects solve most of the network problems. Agile projects focus on the individual needs of customers, and the hybrid model has the highest value; in the hybrid model, in addition to accurately 
knowing the customer's needs and solving his pain points, While processing timeliness is greatly reduced, it can also avoid excessive resource investment, save a lot of service repair costs, and improve customer satisfaction and corporate competitive advantages.

The future $5 \mathrm{G}$ will be a new generation that will subvert the industry boundaries. Various unimaginable and innovative products and services will also be introduced. Whether the hybrid model can continue to perform its functions, I will further study the mystery. This research use field research methods to explore the application of three project models to improve the network quality of the telecommunications industry. The research results show that if these three modes are fully used in various situations, they will achieve quite good results. Traditional projects solve most of the network problems. Agile projects focus on the individual needs of customers, and the hybrid model has the highest value; in the hybrid model, in addition to accurately knowing the customer's needs and solving his pain points, While processing timeliness is greatly reduced, it can also avoid excessive resource investment, save a lot of service repair costs, and improve customer satisfaction and corporate competitive advantages.

The future $5 \mathrm{G}$ will be a new generation that will subvert the industry boundaries. Various unimaginable and innovative products and services will also be introduced. Whether the hybrid model can continue to perform its functions, I will further study the mystery.

\section{REFERENCES}

Crawford LH, Helm J. Government, and Governance: The Value of Project Management in the Public Sector. Project Management Journal. 2009;40(1):73-87. DOI:10.1002/pmj.20107

Gordana Lozo, Slobodan Jovanovic. A Flexible Hybrid Method for IT Project Management.

Journal of Emerging Trends in Computing and Information Sciences. VOL. 3, NO. 7 July 2012

James P. Lewis(2010). Mastering project management (2 ed.). Taiwan, McGraw-Hill

Owen, Robert, Koskela, Lauri, Henrich, Guilherme, and Codinhoto, Ricardo (2006). Is Agile Project Management Applicable to Construction? In Proceedings IGLC-14, July 2006, Santiago, Chile. IGLC, pp. 51-66. (Unpublished)

Roger Atkinson, Lynn Crawford, Stephen Wardd. Fundamental uncertainties in projects and the scope of project management.International Journal of Project Management.Volume 24, Issue 8, November 2006, P687-698

R Rao, Connecting organization strategy to projects: the missing link. X Solutions. - 2007 PMI GLOBAL CONGRESS PROCEEDINGS, 2007

Tony Grundy. Strategy implementation and project management. International Journal of Project Management.Volume 16, Issue 1, February 1998, Pages 43-50 